\title{
Context Aware Information Model for Active Learning Object
}

\author{
Asta SLOTKIENE \\ Vilnius Gediminas Technical University, Saulètekio al. 11, 10223 Vilnius, Lithuania \\ asta.slotkienedvgtu.lt
}

\begin{abstract}
This paper presents how to express and describe context of learning content, which enables the design of active learning object (ALO) and their educational content, prediction of active learning process and creation of problematic learning situations. For this purpose, in the paper we proposed an ALO information model, which uses context of educational content and meaningful action of learners. This paper also analyses the results of research and shows that while developing ALO, its reusability is not lost
\end{abstract}

Keywords: active learning object, information model, authoring context, LO reusability, LO specification

\section{Introduction}

The most famous works of the last decade are related to the learning object (LO) architecture solutions (Polsani, 2003; Wiley, 2003), which decide how to divide LO into logical or physical units as well as how to increase the reusability and flexibility of LO. Another relevant objective under consideration is related to the role of context in the development and application of LO (Jovanovich, 2008 and Koehler et al., 2009). According to the authors (Ignatova et al., 2015; Weitl, 2004 ), the same LO, its part or another combination of learning units constituting it, transferred into other context of learning activities or learning content also improve the possibilities of its reusability. On the other hand, the process of learning and its content assimilation and perception are ensured not only by the available hardware and software, but also by the creation of purposefully selected e-learning situations and their application, enhancing an active participation of the learner, when the learning content is perceived by interactive meaningful actions that convey and develop knowledge (Slotkiene, 2009). Today active e-learning environments are implemented by applying a variety of active learning methods: virtual or remote laboratory, assessment tests of knowledge and skills, experimental tasks, discussions, online collaboration tools, etc. This paper analyses active learning process, which includes interactive actions that encourage thinking and decision making. Learning situations is composed of action, such as the change of object position, selection of input values to stimulate events, structure formation of the given objects, etc.

In the paper we look for a solution, balancing the preservation educational context and reusability of active learning object. We analyse how to express and to describe 
educational context, meaningful action of learners, authoring context of problematic learning situations, which require decisions.

\section{Active learning objects and their characteristics}

According to Bang and Dalsgaard (2006), "learning objects become useful in the learning process only when the learner applies them usefully. The essential thing is creation of respective learning activity". ALO is normally understood as the set of the smallest undividable objects of learning content designed for reaching a concrete learning goal. However, such adaptation of LO understanding to the concept of an active learning object contradicts the principle of active learning: active learning is based on the learner's activity, when the learning content is perceived by interactive meaningful actions which convey and form knowledge. This type includes such interactive actions as the change of object position, selection of input values to stimulate event, structure formation of the given objects etc. During its application, an active learning object performs the following functions: stimulates application of the experience; conveys the learning material through problematic situations; encourages the performance of interactive actions and assessment of reasonability of problematic situation solution. According of several authors, ALO are formed by taking into consideration the following statements (Jovanovich, 2008; Strijker, 2006):

- ALO is not clear granulated information, i.e. information units comprising it are interrelated and interlinked semantically.

- ALO is not merely the object of practice or evaluation. Ability to apply knowledge cannot be elaborately compound of exact sequence of actions; it must reflect substantial quality changes in thinking.

- $\quad$ ALO as a unit is not an object reusable in different e-learning environments; it rather provides a possibility of reusability on the level of action or in case of the change in learning circumstances.

\section{Information model active learning object design}

The formation of information model of ALO is comprised of the following two main stages: analysis and expression of the content of one learning topic and description of information model ALO.

The main and the most important stage is the analysis of learning topic content conveyed by the ALO. For this purpose, scholars (Burbaite et al., 2014; Bang et al., 2006) propose ALO information models used for linking learning components comprising ALO with semantic relations thus creating applicable scenarios of e-learning and for providing learning objects according to the sequence determined beforehand or according to the sequence selected by the system of individual abilities. However, their essential noticeable limitation is that they do not describe the semantic structure of the ALO reusability part. This affects the flexibility of ALO usage and its reusability by author's modification of the active learning object, i.e. by adjusting it to other learning goals (Slotkienè, 2009).

For the formation of ALO information model we suggest using the concept of context defined by Brezillon (Vieira et al., 2008) based on the application of a focus which allows to regard the dynamism of context under the change of circumstances. We 
have also used the concepts of contextual modelling and their interrelationships proposed by Vieira (Vieira et al., 2008) (focus, entity, contextual elements). Formation process of ALO information model is shown in Fig. 1.

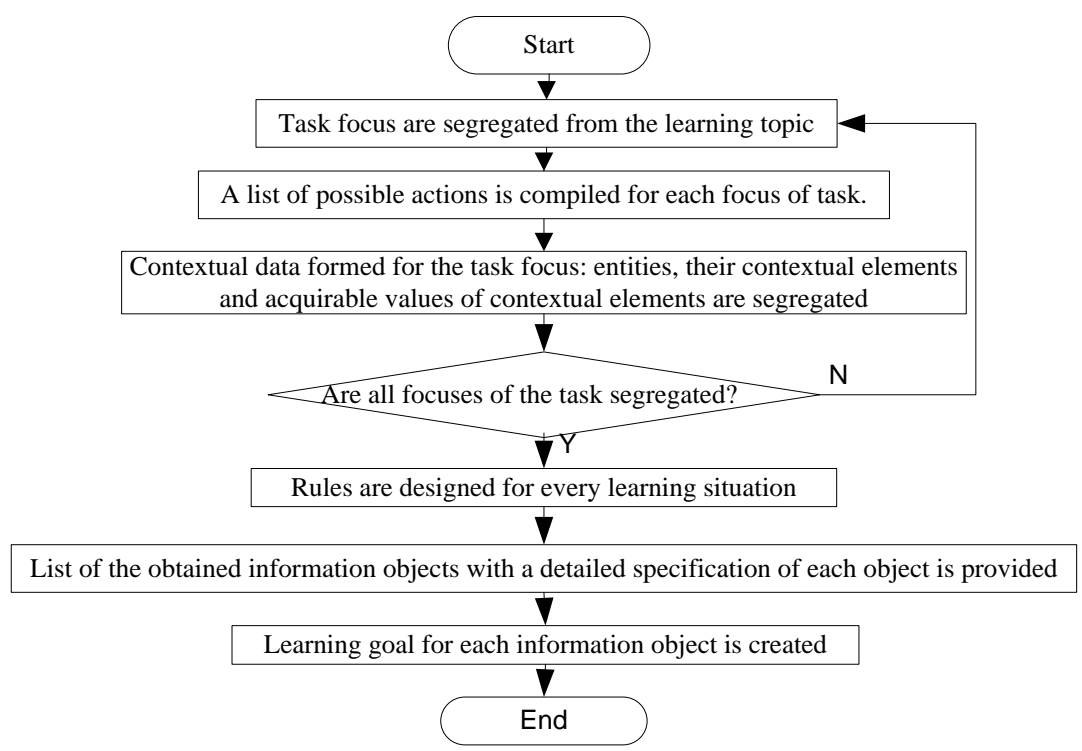

Figure 1. Formation algorithm of ALO information model

Formation of the ALO information model includes four major stages:

1. In order to express the context of the learning topic content, task focuses are used the application whereof helps to define the essential aspects of the analyzed subject field.

2. Contextual data are specified for each focus of the task: entity, contextual element and the value of the contextual element. They describe objects segregated from the context of the learning topic content, their features and the values they acquire.

3. Rules are designed which describe the learning situation and respectively influence the decision making process, i.e. the performance of action which enables the application of the simulation-based learning in the process of learning.

4. Obtaining all information object (learning situations) comprising the ALO IM. The ALO author is presented with a detailed description of each learning situation and their metadata: semantic density and difficulty level. A generalized created ALO information model is provided in the Fig. 2. 


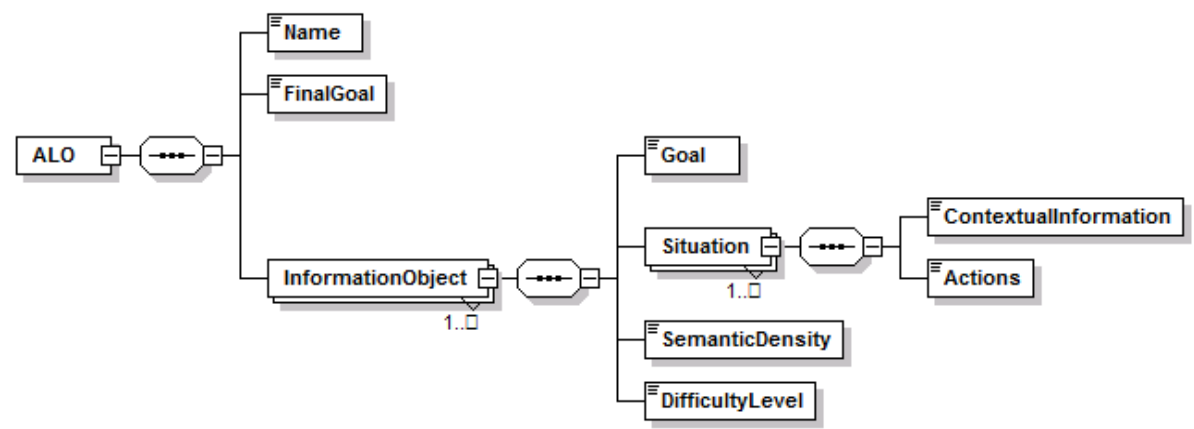

Figure 2. The ALO information model

When having an ALO information model and authoring context of each learning situations, an author of ALO (teaching expert, lecturer) implements according to it the active learning object in the chosen software and applies the developed ALO in a variety of educational contexts of application by providing possibilities of flexible learning (see Fig. 3).

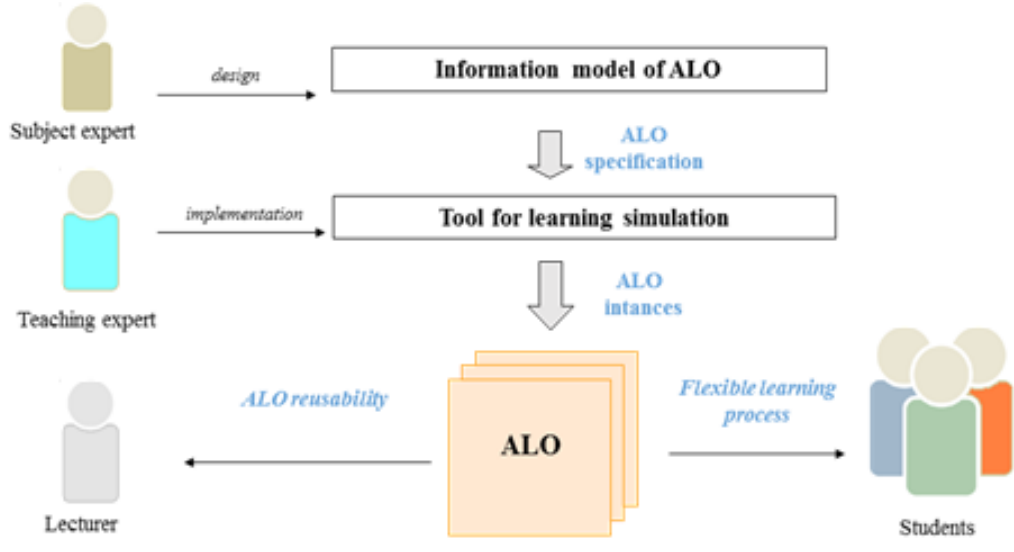

Figure 3. The ALO life cycle

In the present paper, the flexibility of ALO application is ensured from the user's (ALO developer's or learners) perspective, i.e. he may adjust the active learning object according to the demands and abilities himself.

The created ALO information model has the following characteristics

1. Detailed granularity of the ALO IM structure enables one to express the semantic structure of the ALO of the learning topic under consideration.

2. Data elements comprising the information model are related semantically, whereas the interdependence of the information objects is expressed by the contextual data.

3. An expert of the subject creates an ALO information model and receives the semantic structure of information objects comprising the information model, according to which learning situations are created on physical level. 
4. The learning situations realized by the information object seeks one minor goal, whereas altogether they (i.e. the active learning object) seek the common major goal

\section{Research of ALO information model}

In order to specify the advantages of the ALO information model, we have conducted a study. In the process of the study two ALOs of the algorithm course with analogous learning content (sorting algorithms) were created. Their major difference was that the first ALO was created not used information model, the other was created by using the expression and description stages of the developed ALO information model, and its learning situations were formed according to the authoring context of ALO. In the study we hypothesize that an active learning object developed do not use information model is characterised by stronger dissimilarity of the interrelated learning content which is subject to the intuitive implementation of ALO by the expert of the learning topic.

During the study, a similarity matrix of active actions (e.g. entering/selection of data, entering/selection of logical phenomenon, employment of data entry block etc.) existing in both above mentioned tasks of active learning objects related to the learning content has been developed. In order to study this dependence, we have applied the method of correlation analysis, i.e. the object dissimilarity and similarity score. It enables one to quantifiably define the dependence or independence degree of ALO learning situations.

Suppose learning situations defining $X_{I}$ may carry $\mathrm{p}$ characteristics which describe the validity or invalidity of the reusability of active actions. When an active action related to the learning content is applied, then $x_{i}^{(s)}=1$; when it is not applied, $x_{i}^{(s)}=0$. Then object $X_{i}$ is described by a vector:

$$
X_{i}=\left(x_{i}^{(1)}, x_{i}^{(2)}, \ldots, x_{i}^{(p)}\right), \text { here } x_{i}^{(s)} \in\{0,1\}
$$

For the creation of similarity scores of two learning ALO learning situations, frequencies of $\left(x_{i}^{(s)}, x_{j}^{(s)}\right)$ values specifying the similarity or dissimilarity of a feature are used. Since the aim of the learning component assessment is to show their dissimilarity within the limits of ALO, the absence of the relevant feature, i.e. the frequencies of the following pairs is $(0 ; 0),(0 ; 1),(1 ; 0)$. We suggest evaluating this by applying the Lance-Williams dissimilarity score.

$$
r\left(X_{i}, X_{j}\right)=\frac{v_{i j}^{(01)}+v_{i j}^{(10)}}{\left(2 v_{i j}^{00}+v_{i j}^{01}+v_{i j}^{10}\right)}
$$

The obtained results of dissimilarity score of both ALO learning situations have shown that creation of ALO with the use of ALO information model where its semantic structure is designed enables us to achieve greater intersimilarity of the realized learning situations with respect to the active actions. The average value of dissimilarity criterion of interactive actions related to the educational content of the designed ALO learning situations is not less than that of ALO without information model. This demonstrates that it would be complicated to apply the latter ALO for flexible learning, i.e. to adjust the ALO to the changed characteristics of the learning process, since interrelation of its learning situations in the learning content is weaker. By employing the scale of 
evaluating the correlation rate we have compared the dissimilarity score of both ALO learning situations.

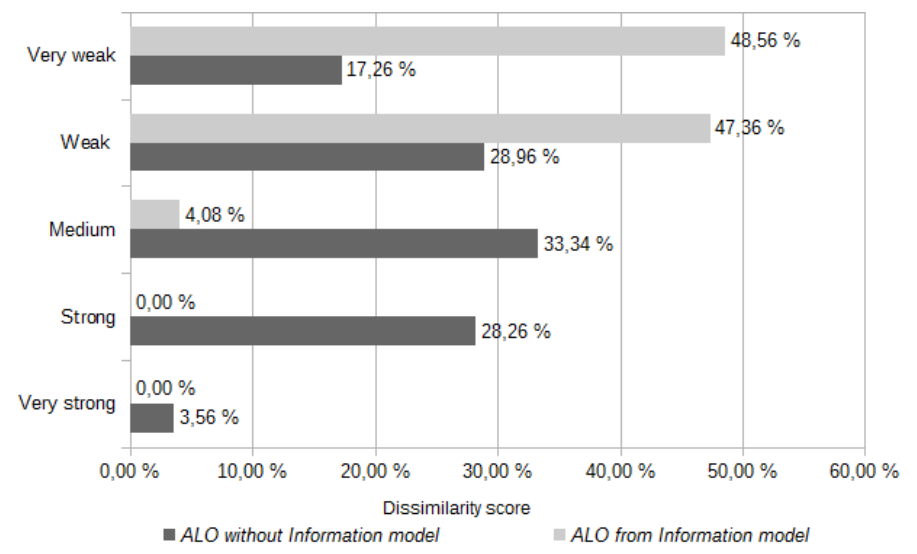

Figure 4. Distribution of the ALOs dissimilarity score

The diagram (see Fig. 4) shows that learning situations of ALO information model are characterised mostly weak (48\%) or very weak $(47 \%)$ dissimilarity score, and almost 28 of ALO (created without information model) are characterised by strong dissimilarity score and $33 \%$ are characterised by average dissimilarity score.

Summarising the results of the study we may state that the study hypothesis was confirmed. If an expert of the subject develops an ALO without a prior analysis and description of its educational content, learning situations of such implemented ALO are twice weaker related with regard to the learning content than those of ALO information model.

\section{Conclusions}

The analysis of the subject field prior to the implementation of the object or software under development is an important stage of the engineering process determining the results of successive stages. The conducted study proves that this is true about ALO as well. When an expert of the learning topic first of all to describe authoring context of ALO, after a thorough analysis of educational content, then he creates ALO learning situations, which are more similar to each other in the learning content. This initial process of ALO development enables us to increase the reusability of ALO, but do not loss educational context. Thus the time spent on the implementation of single learning situations (ALO developed without information model), characterised by large variability of the educational content, and may be used for ALO information model and for the developing of flexible and reusability ALO from their information model. 


\section{References}

Bang, J, Dalsgaard, C. (2006). Rethinking e-learning. Shifting the focus to learning activities, In: O Murchú, D., Sorensen, E. (eds.). Enhancing Learning Through Technology, Information Science Publishing, Hershey; London; Melbourne; Singapore. 184-202.

Burbaite, R., Bespalova K., Damaševičius, R., Štuikys, V. (2014). Context-aware generative learning objects for teaching computer science. // International journal of engineering education. Dublin: TEMPUS Publications. ISSN 0949-149X, Vol. 30, No. 4, p. 929-936.

Jovanovich, J. (2008). Generating Context-related Feedback for Teachers. International Journal of Technology Enhanced Learning (IJTEL), Vol. 1, No.1/2, pp. 47 - 69.

Ignatova V., Dagienė V., Kubilinskienè S. (2015). ICT based learning personalization affordance in the context of implementation of constructionist learning activities. Informatics in Education -An International Journal, Vol. 14, No. 1, 51-65.

Koehler, M., Mishra, P. (2009). What is technological pedagogical content knowledge (TPACK)? Contemporary Issues in Technology and Teacher Education, 9(1), 60-70.

Polsani, P. (2003) Use and abuse of reusable learning objects. Journal of Digital Information, Vol. 3, No. 4.

Slotkiene A. (2009). Design Methods of Active Learning Object and Research on this Method. Dissertation. Technologija. KTU.

Strijker A., Collis B. (2006). Strategies for reuse of learning objects: Context dimensions. International Journal of E-Learning, Vol. 5, No. 1, p. 89.

Vieira V, Brezillon P, Salgado A. C., Tedesco P. (2008). A context-oriented model for domainindependent context management. Revue d'IntelligenceArtificielle, 22 (5), 609-627.

Weitl F., Kammerl R., Göstl M. (2004). Context aware reuse of learning resources. Proceedings of World Conference on Educational Multimedia, Hypermedia and Telecommunications 2004, p. $2119-2126$

Wiley D. (2003). Learning Object Design and Sequencing Theory. Dissertation for Brigham Young University. Online: http://opencontent.org/docs/dissertation.pdf. 2003.

WEB (a). Reusable learning objects. What are GLO's. Online: http://www.rlo-cetl.ac.uk/whatwedo/glos/whatareglos.php.

Received June 27, 2018, accepted June 27, 2018 